\title{
CINEMA E GAMES: UMA ANÁLISE COMPARATIVA ENTRE O FILME E O JOGO “HARRY POTTER E AS RELÍQUIAS DA MORTE - PARTE 1"
}

\author{
OLIVEIRA, Miqueias (1) \\ RIBEIRO, Ilmarana (2); \\ MARQUES, Larissa (3)
}

(1) UFMA, Bacharelando em Design

E-mail: miqueiasconquer@gmail.com

(2) UFMA, Bacharelanda em Design

E-mail: ribeiroilmarana@gmail.com

(3) UFMA, Bacharelanda em Design

E-mail: larahferro@gmail.com

\section{RESUMO}

Os primeiros games consagrados como Mario Bros obtiveram êxito não somente porque tiveram uma melhoria na estética e na programação, mas, sobretudo, porque narravam uma história. Os games se espelharam no cinema no quesito da narrativa e a partir dessa nova forma de pensar o jogo é que este nicho do entretenimento tornou-se um dos mercados mais lucrativos do século XXI. O artigo explicita a relação entre o cinema e os games, abordando a influência do cinema no desenvolvimento dos games enfocando no estudo estético, no caso, o filme e jogo "Harry Potter e as Relíquias da Morte - parte 1".

\footnotetext{
ABSTRACT

The first games enshrined as Mario Bros' game were successful not only because they had an improvement in aesthetics and programming, but mainly because narrated a story. The games were mirrored in film in the narrative question and from this new way of thinking the game is that this entertainment niche has become one of the most lucrative markets in the XXI century. The article explains the relationship between cinema and games, addressing the influence of cinema in the development of games focusing on the aesthetic study, in this case, the movie and game " Harry Potter and the Deathly Hallows - Part 1".
} 


\section{INTRODUÇÃO}

Um jogo é um sistema formal baseado em regras com um resultado variável e quantificável no qual o jogador se sente comprometido com os resultados e as consequências da atividade são opcionais e negociáveis (CRUZ, 2005, apud JUUL, 2003).

O conceito de videogame por John Salisbury é de que um videogame abrange todas as experiências computadorizadas de jogo onde uma tela é o meio principal de exibição da saída do jogo (CYBIS, Walter et. al., 2010). De acordo com alguns dos aspectos necessários para a realização de um bom game, como usabilidade e jogabilidade, é possível mensurar o grau de imersão do indivíduo sobre a realidade virtual determinada pelo game.

Ferreira (2006) apresenta importante contribuição no que diz respeito a games, cinema e interatividade, tornando-se, portanto, artigo base no que se referem aos conceitos utilizados para a análise e interpretação da revisão bibliográfica aqui apresentada.

Ao longo do texto, serão discorridas questões acerca da importância do cinema na produção, jogabilidade e na construção da narrativa do videogame do ponto de vista do design.

Esse artigo tem como objeto de análise o videogame "Harry Potter e as Relíquias da Morte", que servirá como uma discussão teórica a respeito da visão cinematográfica nos jogos, e de seu uso como parte principal para deter a atenção do usuário.

\section{GAMES E CINEMA: UM BREVE HISTÓRICO DE "DIFERENÇAS CONVERGENTES"}

A era inaugural do cinema mostrou-se um marco na forma de interação entre as pessoas e a arte. De uma maneira guerrilheira, tornou-se a principal fonte de promoção de ideologias e comportamentos. Com o advento da Segunda Guerra, o cinema tornou-se o veículo pelo qual os participantes propagaram seus valores, crenças e preceitos, a fim de convencer as massas que determinada constituição ideológica Ihes seriam benéfica ou prejudicial, a partir do ponto de vista do Estado. O cinema pode ser visto como um meio de propagação de sonhos, de uma construção histórico-social para um fim de escape, como supracitado a Segunda Guerra.

Durante a década de 70 surgem os primeiros videogames, trazendo a solução da necessidade das pessoas interagirem com filmes de uma forma mais profunda e pessoal, uma vez que estilos de vida, gostos e sensações já foram experimentados e validados pelo cinema. Em 1972, nasce o jogo Pong, pelo engenheiro Al Alcorn e pelo empresário Nolan Bushnell, o mesmo criador da Atari. Em 1985, a empresa japonesa Nintendo introduziu o NES (Nintendo Entertainment System), que teve grande êxito no mercado internacional. Os principais fatores para o sucesso do NES incluem o foco em crianças, a facilidade de uso e a qualidade tecnológica (CYBIS, Walter et. al., 2010). 


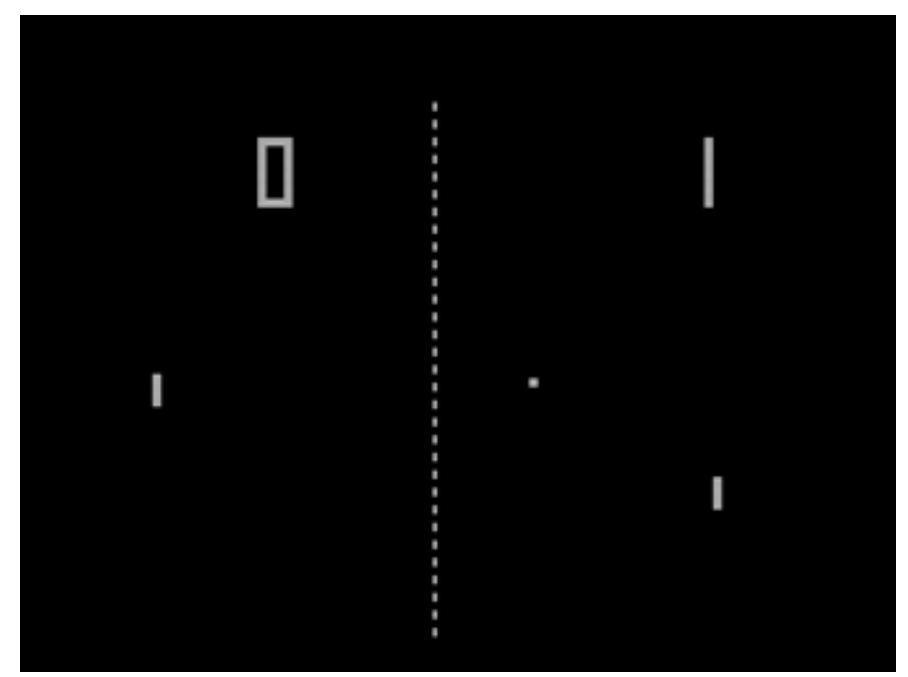

Figura 1. Interface do videogame Pong: jogo icônico na história dos games. Retirado da Revista Forbes (2014)

O surgimento do cinema revolucionou o modo de se fazer arte, uma vez que unificou a pintura, fotografia e a música. Porém, com o avanço crescente da tecnologia e, consequentemente, das técnicas envolvidas, atualmente se presencia a disputa bilionária constante entre tais mecanismos por parte dos grandes estúdios cinematográficos.

Segundo Lopes (2010), todo filme apresenta rigorosamente um personagem, um cenário, o enquadramento, luz, movimento (de um ou de todos os elementos do quadro: da câmera, do personagem, do cenário, luz, entre outros), a ação dramática, a palavra escrita, música, ruídos, falas ou diálogos e ainda, o corte ou montagem, que é a peça chave da edição. E todos os games apresentam essas técnicas de produção (LOPES, 2010).

Assim que foram lançados os primeiros videogames, na década de 70, estes já se utilizavam de técnicas cinematográficas como o "Teatro Filmado", que consiste em um quadro onde toda a narrativa se desenvolve. Em decorrência de constantes investimentos dos fabricantes, os games passaram a adotar o conceito de "movimento de câmera" e evoluíram até chegar aos computadores pessoais, que incorporaram imagens tridimensionais em seus programas e passaram a ser introduzidos aos jogos, os aproximando ainda mais da sétima arte (FERREIRA, 2006).

Como decorrência de tal evolução, nasceu uma das principais diferenças entre o cinema e os videogames: a interatividade. Enquanto, no filme, o telespectador é obrigado a assistir a tudo de forma passiva, os jogos permitem ao mesmo tempo a sensação de agir, influenciar no decorrer da narrativa, avaliar as cenas de ângulos diferentes e se colocar no lugar do protagonista, passando, assim, a ser mais ativo (FERREIRA, 2006). 
A cada dia esse processo interativo fica mais desenvolvido, como pode ser observado nos jogos em rede, nos quais, além de jogar e ser agente, o usuário ainda pode se comunicar e jogar com outras pessoas em diferentes pontos do planeta (multiplayers), o que no cinema não ocorre (FERREIRA, 2006). Por isso, o mesmo tem funcionado como porta de entrada para 0 mundo dos games, despertando nos fãs o anseio de "viver" determinada realidade, ser o agente principal e interferir diretamente na narrativa, mesmo que parcialmente. É possível, inclusive perceber, ao longo dos jogos, reproduções animadas ou traillers dos respectivos filmes que deram origem aos games.

Porém, é sabido que essa interatividade não ocorre de forma plena, uma vez que o jogador, por mais que "altere" o caminho, sempre atinge um objetivo pré-programado, demonstrando que não tem poder total sobre o roteiro do jogo. Essa interatividade, segundo Stateri (2008), baseada na definição de Raymond Williams, não passa de "reatividade". Segundo ela, o ato de agir dentro de uma possibilidade estandartizada, conseguindo assim uma reação esperada, é uma ação reativa (LOPES, 2010, apud STATERI, 2008). A única interatividade real aconteceria entre multi-jogadores online, onde cada um recebe a mensagem do outro e a interpreta de acordo com seus repertórios e experiências antes de dar uma resposta (STATERI, 2008).

O que se observa hoje é o ápice do "remediation", definido como o resultado de um desejo de nossa cultura de multiplicar suas mídias e, ao mesmo tempo, apagar todos os traços dessa medição (BOLTER E GRUSIN, 1996 apud CRUZ, 2005). Pode-se observar que os jogos "remidiam" aspectos do cinema, enquanto que o cinema faz o mesmo com aspectos dos games ao "remidiar" o uso dos gráficos digitais nos efeitos especiais (KING e KRZYWINSKA, 2002 apud CRUZ, 2005).

É possível, então, partir do pressuposto que, mesmo com suas diferenças interacionais, o cinema e os games convergem para imersão do público em suas narrativas, que dão margem para que o mundo imaginário torne-se real e palpável.

\section{A INFLUÊNCIA DO CINEMA NOS GAMES: O CASO "HARRY POTTER E AS RELÍQUIAS DA MORTE - PARTE 1"}

O filme Harry Potter e as Relíquias da Morte - parte 1 (Harry Potter and the Deathly Hallows Part 1), produzido em 2010 e distribuído pela Warner Bros, conduziu à produção do jogo (de mesmo nome) para computador, lançado no mesmo ano e produzido pela Eletronic Arts.

Segundo a sinopse do filme, do site Warner Bros Co., Harry está prestes a completar 17 anos e precisa ser transportado da casa dos seus tios, os Dursley, para um local seguro. Porém, Lord Voldemort, vilão da série, e seus comensais da morte sabem da transferência e preparam-se para atacar. Assim, Harry e seus amigos - Rony Weasley, Hermione Granger, Remo Lupin, Hagrid e "Olho-Tonto" Moody, personagens da série -, tomam a Poção Polissuco (espécie de mágica do universo dos bruxos da série) e assumem sua forma física, na tentativa de despistar o vilão. A missão é bem sucedida, mas Harry, Rony e Hermione passam a ser caçados, exigindo sua fuga. Precisando constantemente mudar de lugar, eles elaboram um plano para 
encontrar e destruir as horcruxes (objetos que contém partes da alma do vilão) que podem eliminar Voldemort de uma vez por todas.

O jogo, por sua vez, recebe primeiramente a influência de roteiro, onde o objetivo principal é localizar e destruir as horcruxes de Voldemort, combatendo seus comensais e sequestradores constantemente, por meio de feitiços, poções e capa da invisibilidade, além de ajudar as pessoas que encontra pelo caminho.

Percebe-se que, assim como no cinema, o jogo foi projetado usando conceitos de câmeras próprias para as telas. Todavia, utiliza-se de uma linguagem mais dinâmica e insertiva para oferecer a experiência em $360^{\circ}$ para o usuário, que, por vezes, aguarda para ter sua imersão no mundo virtual. Normalmente, pode-se traçar como público-alvo fãs da referida saga e, por essa razão, o jogo passa do nível de explicação de sua própria história para o desencadeamento dos fatos, uma característica presente em jogos derivados de filmes. Neste caso, o jogador que tem o contato anterior com o filme tem um "bônus" para um melhor desempenho no jogo.

O referido jogo apresenta uma elaboração visual mediana, pois a imersão do usuário dá-se, anteriormente, pelos livros e filmes, sendo os carros-chefes de toda a franquia, que em todo 0 contexto deixam o mundo de Harry Potter mais claro e aceitável para o fã.

Em suma, o jogo Harry Potter e as Relíquias da Morte recebe grande influência por parte do cinema, pois a franquia fora executada pelos moldes cinematográficos, tornando-o parte secundária, e não um explicador ou aprofundador da história. O jogo derivado do filme visa colocar o usuário em cena para que compartilhe daquele mundo virtual e não pretende explicar detalhadamente o mundo do qual o jogador faz parte.

\section{INTERFACE DO GAME: UMA ANÁLISE DO PONTO DE VISTA ESTÉTICO}

Para que a atividade do gamer possa ser realizada satisfatoriamente, é de grande importância que a interface estabeleça uma ligação coerente entre as duas partes, no que tange à utilidade e a funcionalidade. Sem esses quesitos, a experiência do usuário, certamente, será desestimulante e frustrante para o jogo, já que, nessa situação, a interface tem a tendência em confundir e, assim, atrapalhar o desempenho do jogador.

A interface propicia ao jogador fazer escolhas e alterações no decorrer do jogo, bem como percorrer o ambiente e realizar as etapas para passagem de nível. Segundo Novak (2010), sem uma interface, um game não seria mais que uma apresentação, uma sequência de animação ou um ambiente estático, um jogo que não pode ser jogado. E, para o bom desenvolvimento da interface de um game, é necessário o estudo estético que melhore a usabilidade e a jogabilidade, que, somadas a outros fatores, contribuirão para maior aceitação da realidade artificial criada e, portanto, da imersão do jogador no game.

Löbach conceitua a estética como ciência das aparências perceptíveis pelos sentidos (por exemplo, a estética do objeto), de sua percepção pelos homens (percepção estética) e sua importância para os homens como parte de um sistema sociocultural (estética de valor) (LÖBACH, 2001). 


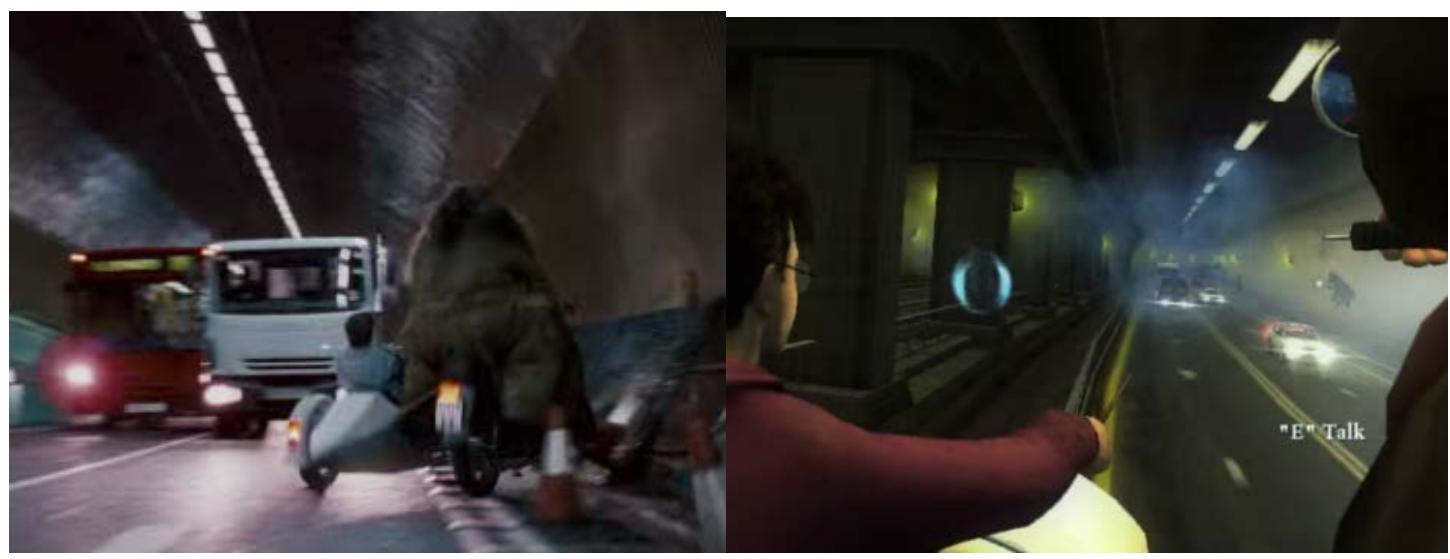

Figura 2. Primeira fase do jogo e a cena do filme "Harry Potter e as Relíquias da Morte parte 1". Retirado de Warner Bros (2010) e Eletronic Arts (2010).

A primeira fase do jogo se dá na fuga de Harry e seus amigos, na qual se evidencia a sensação de perseguição ao protagonista, através de uma mira conturbada, de 360 graus, que objetiva localizar e atingir os inimigos, assim como uma sequência evolutiva do personagem, embora que, muitas vezes, apresente desafios. O game faz uso das cenas de ação, como a fuga de Harry Potter e seus amigos, ilustrada acima. Observa-se, também, o uso de cores e tons escuros, retratando o suspense e a escuridão evidenciada pela imagem onipotente do Lord Voldemort e seus seguidores, os comensais da morte, obrigando o jogador manter-se atento em todo o ambiente à sua volta para não ser derrotado.

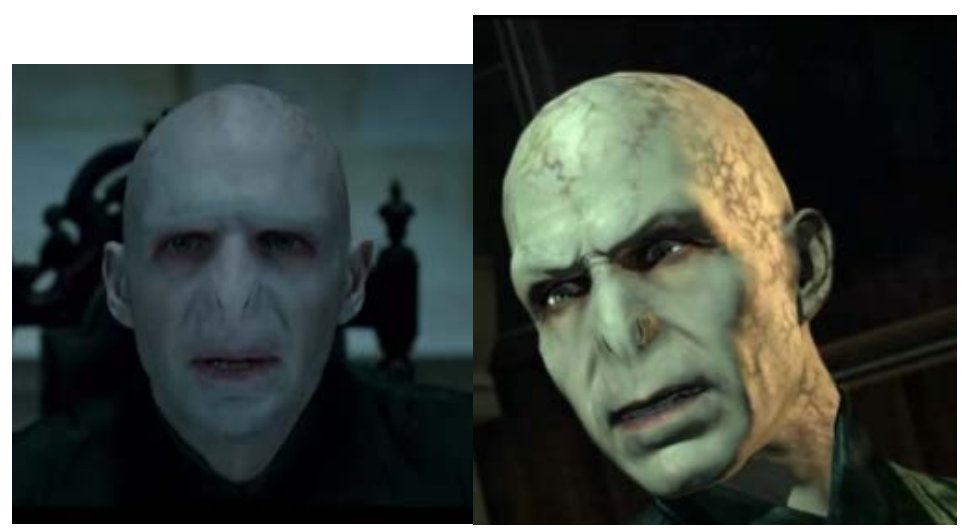

Figura 3. Detalhe comparativo da fisionomia do antagonista no filme e jogo, respectivamente. Retirado de Warner Bros (2010) e Eletronic Arts (2010). 
Os personagens do filme e os avatares seguem uma rigorosa semelhança, no que diz respeito a dublagem, expressões e movimentos, tentando estabelecer ao máximo a veracidade ao jogo. No que diz respeito a jogabilidade, faz-se necessário a exibição de traillers que relacionam 0 game ao filme, ilustrando o objetivo de cada fase.

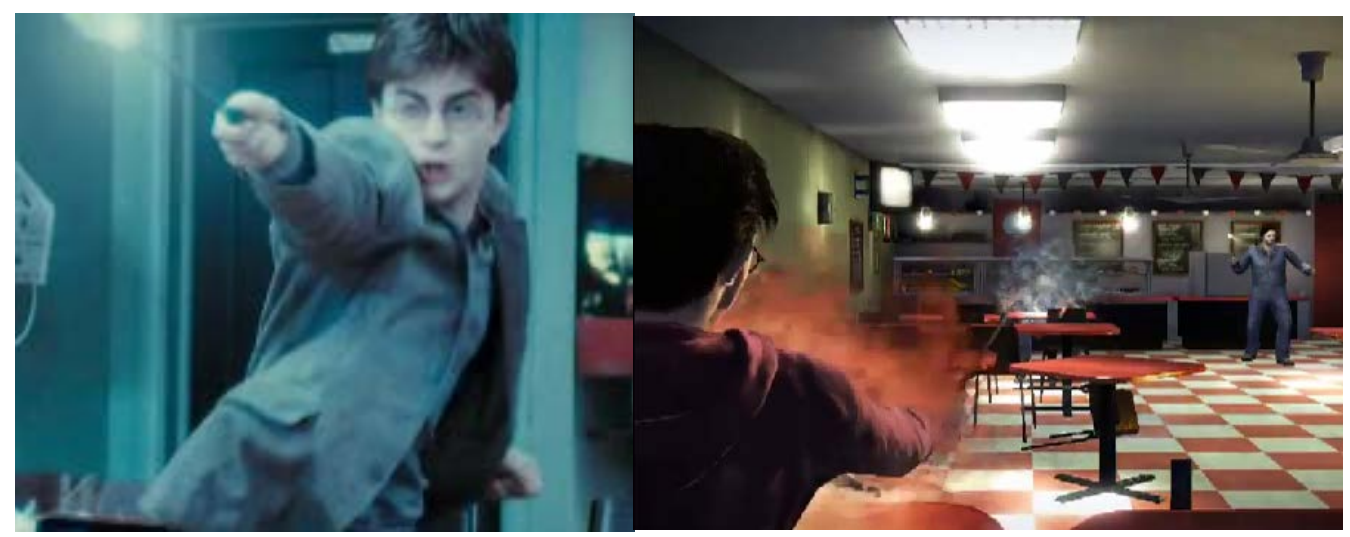

Figura 4. Posições de câmeras diferentes no filme e jogo, representando o conflito na lanchonete. Retirado de Warner Bros (2010) e Eletronic Arts (2010).

O jogo divide as fases de acordo com os momentos de combate direto e a busca pelas horcruxes. As imagens comparativas acima retratam o momento em que Harry, Rony e Hermione se encontram em uma lanchonete e são atacados por comensais da morte a serviço do vilão. Vencida essa etapa, partem em busca da terceira horcruxe: um colar que se encontra sob o poder de Dolores Umbridge.

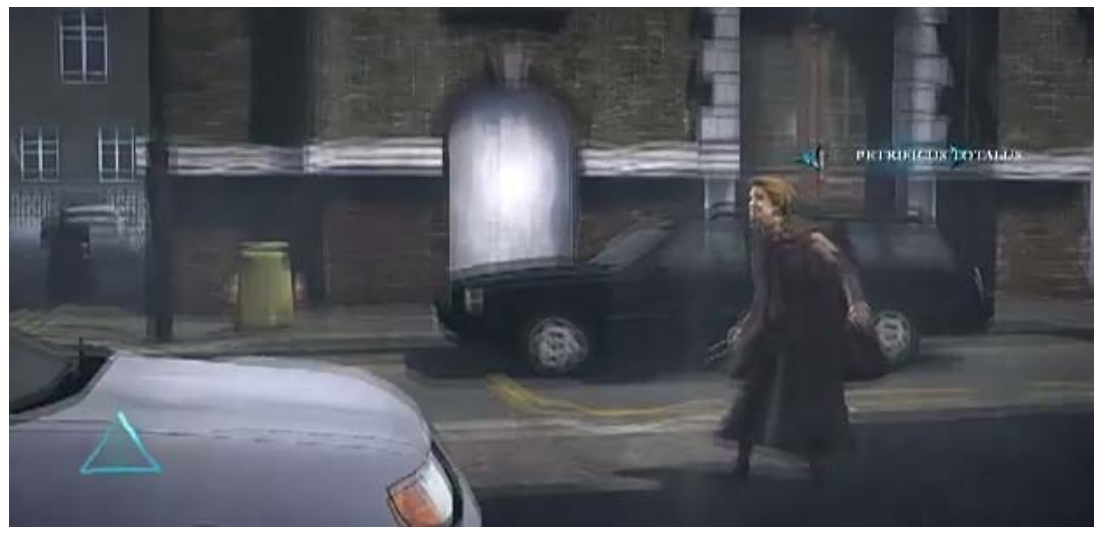

Figura 5. Uso da Capa da Invisibilidade: uma forma de imersão do gamer no jogo. Retirado de Eletronic Arts (2010). 
O jogo requer um conhecimento de todos os filmes, uma vez que se faz necessário conhecer os feitiços, poções e personagens. A imagem acima ilustra claramente isso, pois Harry se coloca sob a capa da invisibilidade para circular entre os inimigos sem ser notado. O efeito embaçado retrata o "tecido" da capa. O triângulo na parte esquerda inferior, demarca o tempo de duração do efeito "invisível" proporcionado pela capa. E na parte direita superior encontram-se os feitiços, que podem ser navegáveis e selecionados de acordo com a ocasião. Portanto, a jogabilidade vai depender também de conhecimentos pré-concebidos tanto dos filmes como dos jogos.

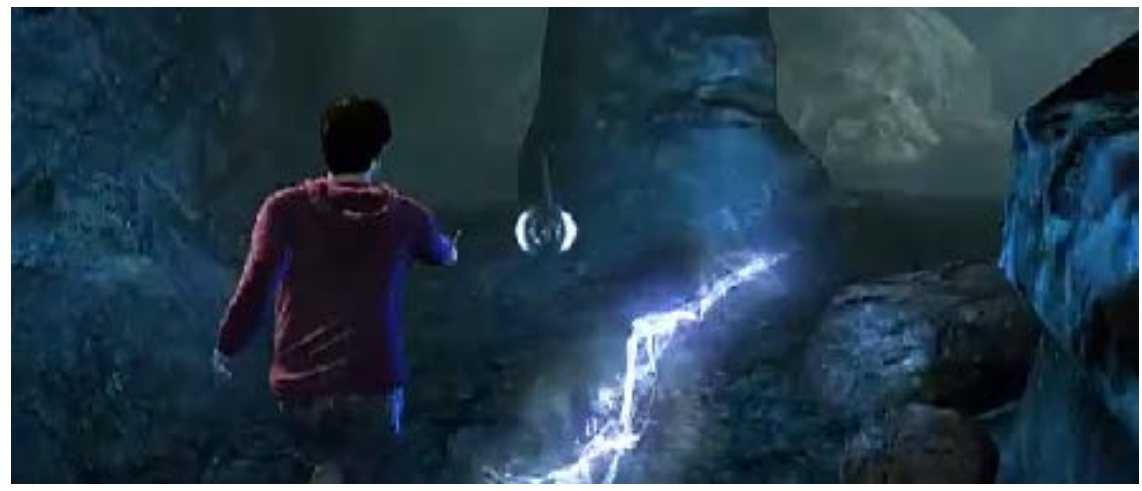

Figura 6. Feitiço lançado mostra o caminho a ser percorrido. Retirado de Eletronic Arts (2010).

Por ser um game de $360^{\circ}$, confusões são inevitáveis no que diz respeito ao melhor caminho a seguir, portanto, o game apresenta uma opção que funciona como uma espécie de "feitiço guia", o que no mundo dos "trouxas" (denominação aos não bruxos, indicada na franquia) funcionaria como um GPS, permitindo ao mesmo, chegar mais rapidamente ao local desejado.

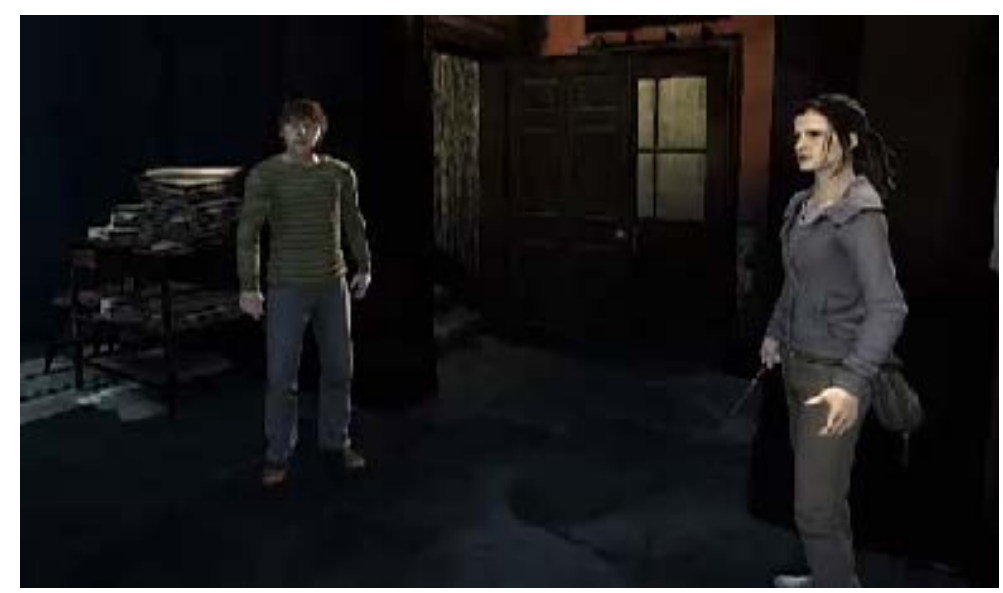

Figura 7. Gamer interagindo com Rony e Hermione. Retirado de Eletronic Arts (2010). 
Ainda no que se refere à jogabilidade, o game se apresenta como single-player. Logo, o único personagem jogável é o protagonista, que é somente acompanhado por seus amigos, Rony e Hermione, que o ajudam com instruções e permitem maior interação, reafirmando a união evidenciada no filme.

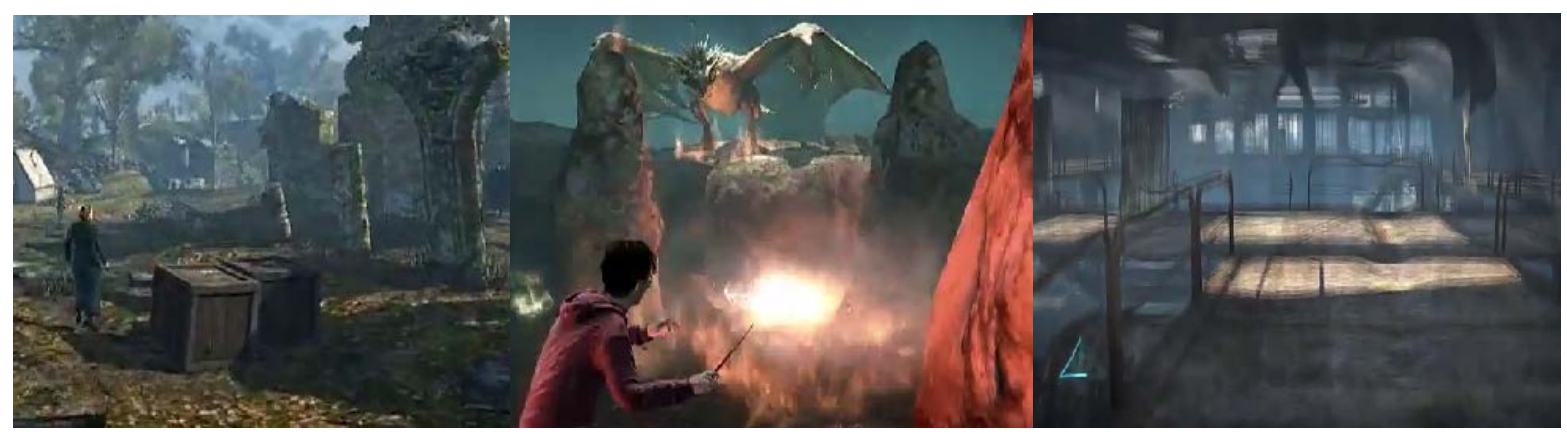

Figura 8. Cenários não pertencentes ao filme que enriquecem o jogo e permitem ao gamer explorar o universo virtual e vivenciar novas experiências. Retirado de Eletronic Arts (2010).

Fazem parte do jogo, também, cenários que não apareceram no filme, para fornecer uma sutil mudança a fim de não deixá-lo monótono e, assim, aumentar o nível de dificuldade, uma vez que assistindo ao filme, o jogador já tem uma noção preconcebida dos lugares e a que caminho deve percorrer.

\section{CONSIDERAÇÕES FINAIS}

O artigo elucida claramente a fronteira entre o cinema e os games de forma objetiva e explicativa. Percebe-se que o jogo é um conjunto aplicado de técnicas cinematográficas, como a imersão e a suspensão de descrença, que almejam a imersão total do jogador em sua atmosfera e a inclusão na narrativa. Pode-se depreender que há uma linha tênue entre essas duas facetas, todavia essas diferenças convergentes é o que mantém o foco do usuário e transporta-o para esse mundo.

Em "Harry Potter e as Relíquias da Morte" pode-se abstrair um contexto diversificado, entretanto, que converge para o mesmo ponto, pois o jogo não precisa explicar sua história do princípio e nem a si próprio, uma vez que exige do usuário/jogador um conhecimento prévio sobre suas referências e cultura, contados nos livros e nos filmes.

Em suma, pode-se partir do pressuposto que o cinema e os jogos são dois modos diferentes de se ver a narrativa, todavia possuem semelhanças no modo de abordar a imersão e de trazer o individuo para sua atmosfera e contexto. O cinema e os jogos devem andar de mãos dadas, pois compartilham de uma raiz mais antiga e profunda, que possibilita uma visão e experiência de pertencimento. 
Esta discussão é uma primeira etapa de uma pesquisa mais abrangente, abrindo espaço para trabalhos mais aprofundados na relação entre cinema e games, permitindo que designers e desenvolvedores possam trabalhar melhor nessa transposição dos filmes para os consoles, trazendo cada vez mais o gamer para o universo da fantasia.

\section{REFERÊNCIAS BIBLIOGRÁFICAS}

CYBIS, Walter; BETIOL, Adriana Holtz; FAUST, Richard. Ergonomia e Usabilidade: Conhecimentos, Métodos e Aplicações. 2. ed. São Paulo: Novatec Editora, 2010.

LÖBACH, Bernd. Design Industrial: bases para a configuração dos produtos industriais. São Paulo: Editora Edgar Blucher Ltda, 2001.

NOVAK, Jeannie. Desenvolvimento de Games. 2. ed. Cengage Learning, 2011.

HARRY Potter e as Relíquias da Morte. Direção de David Yates. Produção de David Heyman. J.K. Rowling e David Barron. Roteiro: Steve Kloves. [s.i.]: Warner Bros, 2010. (146 min.), son., color.

WARNER BROS (Ed.). Harry Potter e as Relíquias da Morte. 2010. Disponível em: <http://harrypotter.br.warnerbros.com/hp7a/\#>. Acesso em: 3 nov. 2014.

Harry Potter e as Relíquias da Morte, parte 1. Eletronic Arts Inc, Warner Bros. Entertainment Inc., 2010.

CRUZ, Dulce Márcia.Tempos (pós-) modernos: a relação entre o cinema e os games. Revista Fronteiras - Estudos Midiáticos. Vol. VII no 03, p. 175 - 184, Setembro/Dezembro 2005.

FERREIRA, Martins Emmanoel. Games, cinema e interatividade. XXIX Congresso Brasileiro de Ciências da Comunicação, 2006, Brasília.

LOPES, Nilson Luiz Rosa. Uma análise da interface Cinema/Videogame. Universidade Federal de Santa Maria. Centro de Educação Superior Norte, 2010, Rio Grande do Sul.

HARRY Potter Relíquias da Morte Part 1 PC GAME (FASE 1). [s.i.]: Lk3 Games, 2013. (15 min.), son., color. Disponível em: <https://www.youtube.com/watch?v=-G_RIHjNZkc>. Acesso em: 07 nov. 2014.

HARRY Potter Relíquias da Morte Part 1 PC GAME (FASE 2). [s.i.]: Lk3 Games, 2013. (13 min.), son., color. Legendado. Disponível em: <https://www.youtube.com/watch?v=oQ4K32RXuKM>. Acesso em: 7 nov. 2014.

HARRY Potter Relíquias Da Morte Part 1 PC GAME (FASE 3). [s.i.]: Lk3 Games, 2013. (25 min.), son., color. Disponível em: <https://www.youtube.com/watch?v=ZWPxoXnedYU>. Acesso em: 7 nov. 2014.

HARRY Potter Relíquias da Morte Part 1 PC GAME (FASE 4). [s.i.]: Lk3 Games, 2013. (17 min.), son., color. Disponível em: <https://www.youtube.com/watch?v=ac0MptfGVl8>. Acesso em: 7 nov. 2014.

HARRY Potter Relíquias da Morte Part 1 PC GAME (FASE 5). [s.i.]: Lk3 Games, 2013. (24 min.), son., color. Disponível em: <https://www.youtube.com/watch?v=qJoshjNRwnl>. Acesso em: 7 nov. 2014.

GUERRA, Guilherme. Harry Potter e as Relíquias da Morte - Parte 1: o jogo. Disponível em: $<$ http://potterheaven.com/jogos/harry-potter-e-as-reliquias-da-morte/harry-potter-e-as-reliquias-da-morteparte-1-o-jogo/>. Acesso em: 10 nov. 2014. 